Erratum

\title{
Erratum to "Quantification of Human and Animal Viruses to Differentiate the Origin of the Fecal Contamination Present in Environmental Samples"
}

\section{Sílvia Bofill-Mas, Marta Rusiñol, Xavier Fernandez-Cassi, Anna Carratalà, Ayalkibet Hundesa, and Rosina Girones}

Laboratory of Viruses Contaminants of Water and Food, Department of Microbiology, Faculty of Biology, Avenida Diagonal 643, 08028 Barcelona, Catalonia, Spain

Correspondence should be addressed to Sílvia Bofill-Mas; sbofill@ub.edu

Received 13 May 2014; Accepted 21 July 2014; Published 28 August 2014

Copyright (C) 2014 Sílvia Bofill-Mas et al. This is an open access article distributed under the Creative Commons Attribution License, which permits unrestricted use, distribution, and reproduction in any medium, provided the original work is properly cited.

The primer Q-PAdV-R was mismatched with probe Q-PAdV-

$P$ in Table 1 . The table is corrected here. 
TABLE 1: Oligonucleotide primers and probes used for the detection and quantification of viral indicators.

\begin{tabular}{|c|c|c|c|c|}
\hline $\begin{array}{l}\text { Primers and } \\
\text { probes }\end{array}$ & Virus & Position $^{\mathrm{a}}$ & Reference & Sequence $\left(5^{\prime}-3^{\prime}\right)$ \\
\hline $\mathrm{ADF}$ & \multirow{3}{*}{$\begin{array}{l}\text { Human adenovirus } \\
\text { (HAdV) }\end{array}$} & $18869-18887$ & \multirow{3}{*}[26]{} & CWTACATGCACATCKCSGG \\
\hline $\mathrm{ADR}$ & & 18919-18937 & & CRCGGGCRAAYTGCACCAG \\
\hline ADP1 & & 18889-18916 & & FAM-CCGGGCTCAGGTACTCCGAGGCGTCCT-BHQ1 \\
\hline JE3F & \multirow{3}{*}{$\begin{array}{l}\text { JC polyomavirus } \\
\text { (JCPyV) }\end{array}$} & $4317-4339$ & \multirow{3}{*}[27]{} & ATGTTTGCCAGTGATGATGAAAA \\
\hline JE3R & & $4251-4277$ & & GGAAAGTCTTTAGGGTCTTCTACCTTT \\
\hline JE3P & & $4313-4482$ & & FAM-AGGATCCCAACACTCTACСССАССТAAAAAGA-BHQ1 \\
\hline QB-F1-1 & \multirow{3}{*}{$\begin{array}{l}\text { Bovine polyomavirus } \\
(\mathrm{BPyV})\end{array}$} & $2122-2144$ & \multirow{3}{*}[28]{} & CTAGATCCTACCCTCAAGGGAAT \\
\hline QB-R1-1 & & $2177-2198$ & & TTACTTGGATCTGGACACCAAC \\
\hline QB-P1-2 & & $2149-2174$ & & FAM-GACAAAGATGGTGTGTATCCTGTTGA-BHQ1 \\
\hline Q-PAdV-F & \multirow{3}{*}{$\begin{array}{l}\text { Porcine adenovirus } \\
(\text { PAdV) }\end{array}$} & 20701-20718 & \multirow{3}{*}[29]{} & AACGGCCGCTACTGCAAG \\
\hline Q-PAdV-R & & $20751-20768$ & & AGCAGCAGGCTCTTGAGG \\
\hline Q-PAdV-P & & $20722-20737$ & & FAM-CACATCCAGGTGCCGC-BHQ1 \\
\hline qOv_F & \multirow{3}{*}{$\begin{array}{l}\text { Ovine polyomavirus } \\
(\mathrm{OPyV})\end{array}$} & \multirow{3}{*}{$\mathrm{VP} 1^{\mathrm{b}}$ region } & \multirow{3}{*}[30]{} & CAGCTGYAGACATTGTGG \\
\hline qOv_R & & & & TCCAATCTGGGCATAAGATT \\
\hline qOv_P & & & & FAM-ATGATTACCAAGCCAGACAGTGGG-BHQ1 \\
\hline Q-PaV-F & \multirow{3}{*}{$\begin{array}{l}\text { Chicken/turkey } \\
\text { parvovirus } \\
(\mathrm{ChPV} / \mathrm{TuPV})\end{array}$} & $3326-3345$ & \multirow{3}{*}[31]{} & AGTCCACGAGATTGGCAACA \\
\hline Q-PaV-R & & $3388-3407$ & & GCAGGTTAAAGATTTTCACG \\
\hline Q-PaV-Pr & & $3356-3378$ & & 6FAM-AATTATTCGAGATGGCGCCCACG-BHQ1 \\
\hline
\end{tabular}



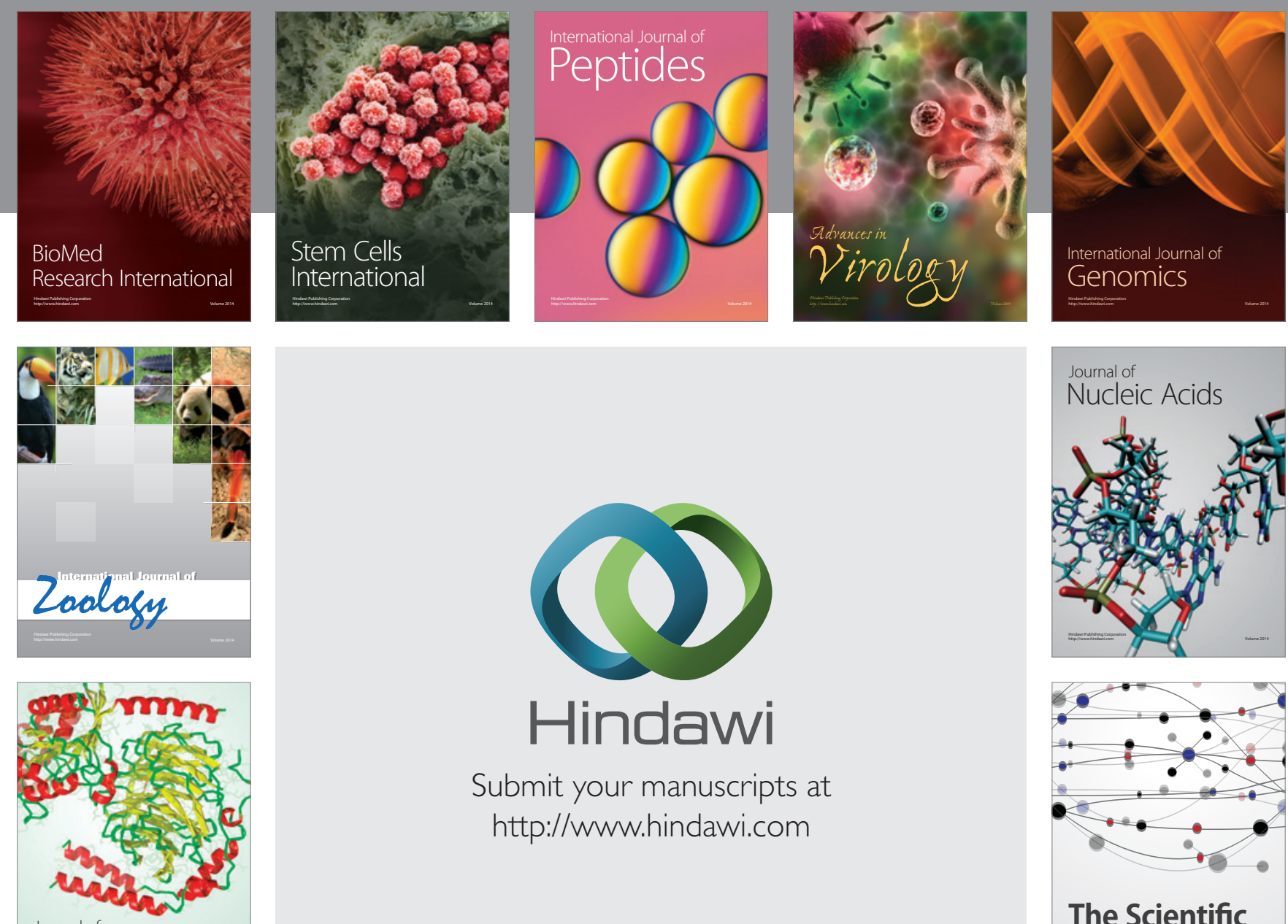

Submit your manuscripts at

http://www.hindawi.com

Journal of
Signal Transduction
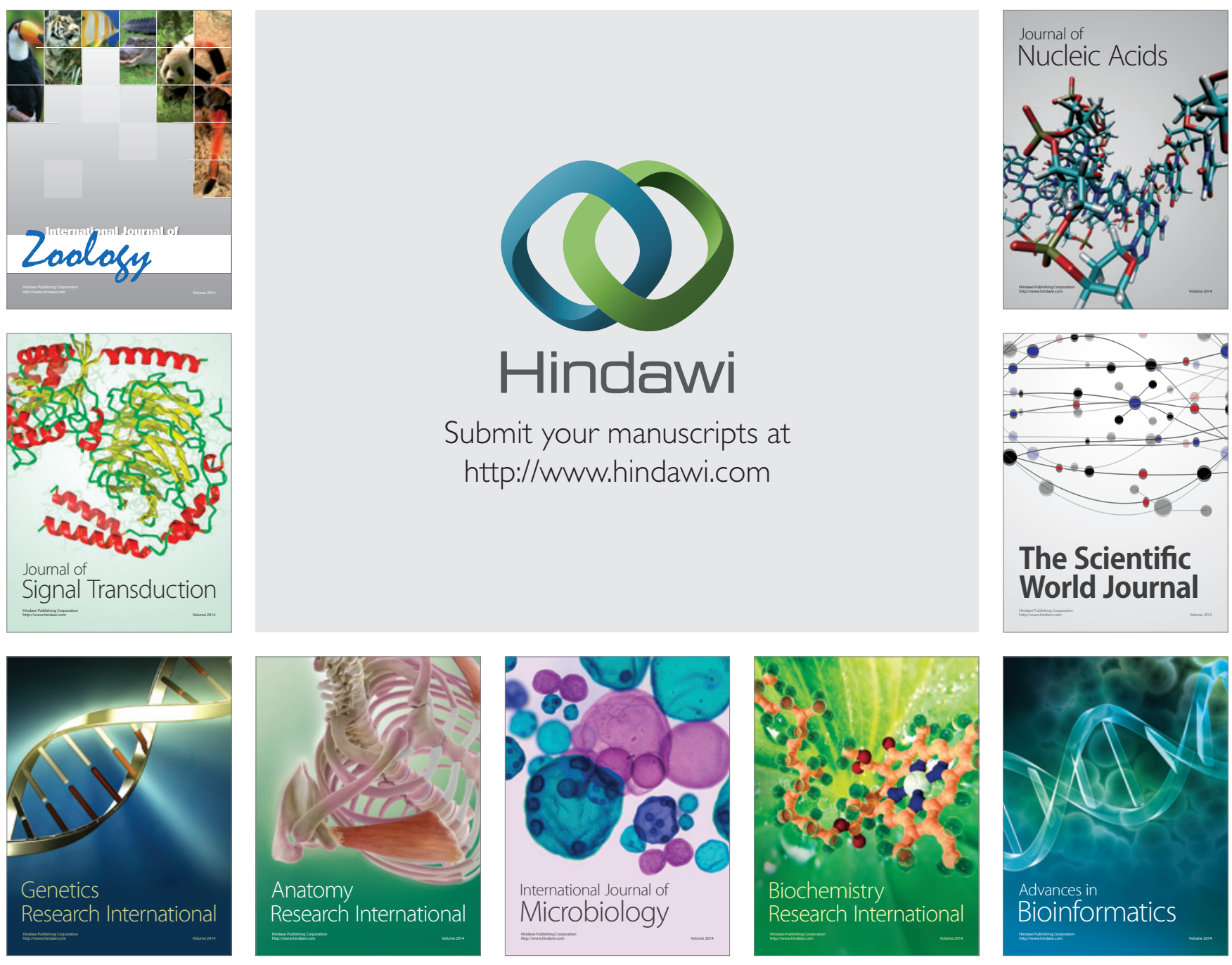

The Scientific World Journal
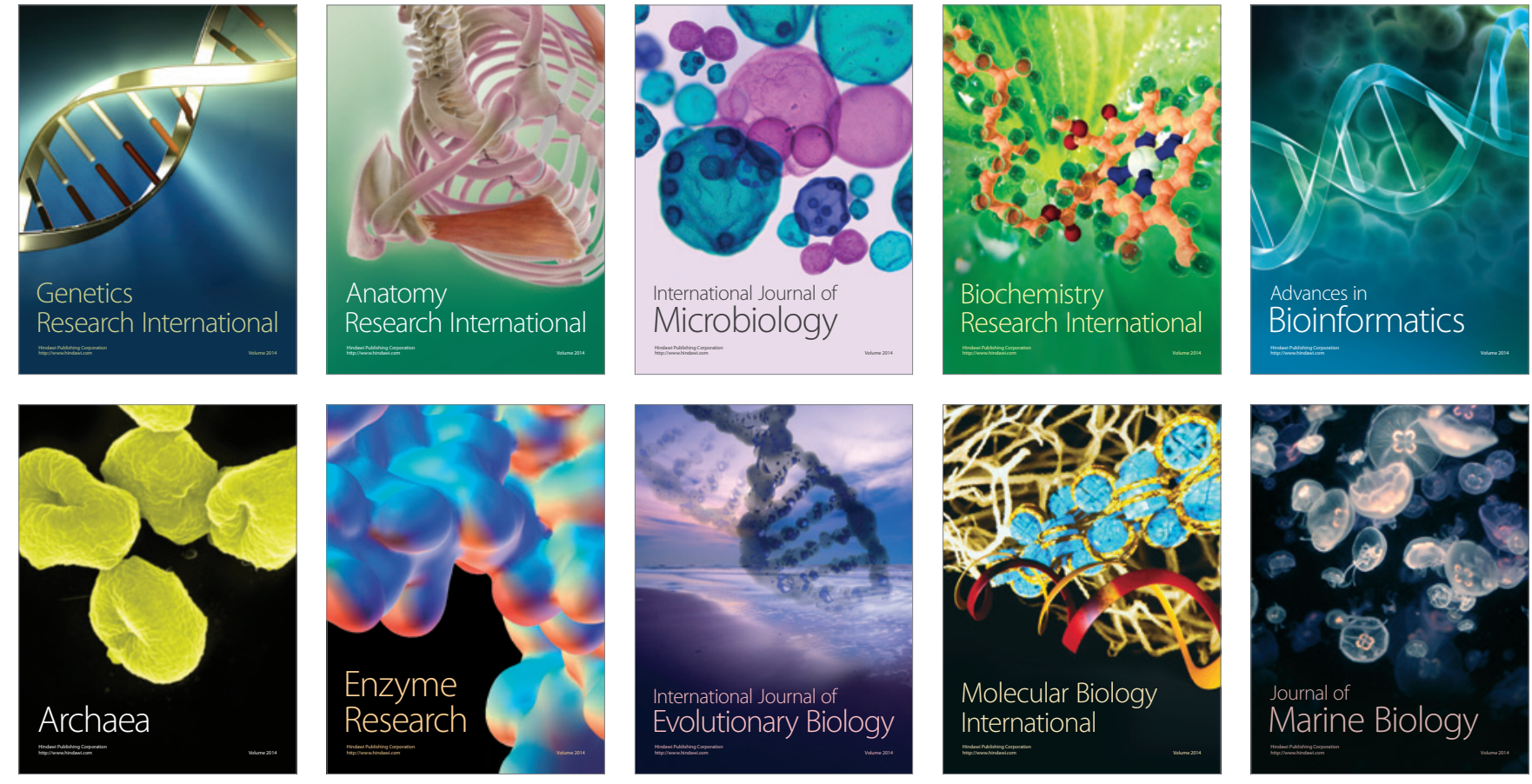